\title{
Fatores condicionantes da (in)satisfação docente no curso de educação física da faculdade La Salle Lucas do Rio Verde
}

\author{
Simone Gobi Marcolan \\ Faculdade La Salle Lucas do Rio Verde - Rede La Salle \\ (simone.marcolan@faculdadelasalle.edu.br) \\ Thallisson Carpeggiani Juliani \\ Faculdade La Salle Lucas do Rio Verde - Rede La Salle \\ (thallissoned.fisica@hotmail.com)
}

\begin{abstract}
Resumo: A satisfação ou insatisfação no trabalho, inclusive no trabalho docente, influencia na satisfação ou insatisfação na própria vida, no comportamento, na saúde, e diretamente na motivação e qualidade do trabalho desenvolvido. Conforme o que o professor busca e o que ele realmente encontra no decorrer do seu ofício, este pode manifestar satisfação, insatisfação, realização profissional, motivação para prosseguir ou desistir, e até mesmo adoecer. Dessa forma, a questão que direcionou a presente pesquisa foi: Quais os principais fatores condicionantes da in(satisfação) profissional dos professores do Curso de Educação Física da Faculdade La Salle de Lucas do Rio Verde MT? De modo geral, buscou-se descobrir quais são os principais fatores condicionantes da (in)satisfação profissional desses professores. Os sujeitos foram 09 professores do referido Curso, atuantes nas três turmas em andamento do $1^{\circ}$ semestre/2018, que responderam um questionário previamente elaborado de acordo com os objetivos da pesquisa. Foi possível descobrir que os professores atuam em uma Instituição e Curso que contribuem para a sua satisfação e realização pessoal e profissional. Mesmo que em alguns pontos encontram-se insatisfeitos, os fatores promotores da satisfação se sobressaem e permitem que ainda se encantem pela profissão que escolheram e a assumam com compromisso, preocupação e responsabilidade.
\end{abstract}

Palavras-chave: Professores de Educação Física. Atuação Profissional. (In)Satisfação Docente.

\section{Conditioning factors of (in) satisfaction teacher in the physical education course from La Salle Lucas do Rio Verde}

Abstract: Satisfaction or dissatisfaction at work, including teaching, influences satisfaction or dissatisfaction in one's life, behavior, health, and directly in the motivation and quality of the work performed. According to what the teacher seeks and what really finds in the course of your job, the teacher may express satisfaction, dissatisfaction, professional fulfillment, motivation to continue or give up, and even get sick. Thus, the question that directed the present research was: What are the main conditioning factors of the professional (in) satisfaction of the teachers of the Physical Education Course at the La Salle Lucas College of Lucas Rio Verde MT? In general, we sought to find out what are the main factors conditioning the professional (in) satisfaction of these teachers. The subjects were 09 teachers of the referred Course, working in the three ongoing classes of the 1st semester / 2018, who answered a questionnaire previously prepared according to the research objectives. It was found that the teachers work in an institution and course that contribute to their satisfaction and personal and professional achievement. Even if at some points they are dissatisfied, the factors that promote satisfaction stand out and allow them to still be enchanted by their chosen profession and to assume it with commitment, concern and responsibility.

Keywords: Physical Education Teachers. Professional performance. Teacher (In) Satisfaction.

\section{INTRODUÇÃO}

A satisfação ou insatisfação no trabalho, e especialmente no trabalho docente, influencia na satisfação ou insatisfação na própria vida, no comportamento, na saúde, e diretamente na motivação e qualidade do trabalho desenvolvido. Alguns 
autores (ESTEVE, 1992; 1999; NÓVOA, 1999; LIBÂNEO, 2011) já têm estudado e discutido esse tema, levando em consideração as reformas educacionais e políticas de trabalho, mudanças sociais, econômicas e culturais.

Diante dessa realidade está o professor, aquele que tem que saber lidar com o conhecimento sistematizado e institucionalizado, sua área formação e atuação, e muitas outras responsabilidades e deveres atualmente atribuídos à profissão, como o de desempenhar papéis que são exclusivos da família ou de profissionais da saúde, o que acaba por descaracterizar a sua profissão. De acordo com o que o professor busca e o que ele realmente encontra no decorrer do seu ofício, este pode manifestar satisfação, insatisfação, realização profissional, motivação para prosseguir ou desistir, e até mesmo adoecer.

Essa profissão sempre foi razão de orgulho para o professor e sua família, respeitado e admirado por todos. Uma profissão de prestígio e reconhecimento. Atualmente, isso está se perdendo, sendo extremamente desvalorizado, inclusive na questão salarial. A sociedade demonstra que deixou de acreditar na educação como "promessa de um futuro melhor; os professores enfrentam a sua profissão com uma atitude de desilusão e de renúncia, que se foi desenvolvendo em paralelo com a degradação da sua imagem social" (ESTEVE, 1999, p. 95). Somado a isso, os professores estão com excesso de horas de trabalho, muitas vezes atuando em mais de uma instituição, o que significa também uma sobrecarga de atividades como preparo de aulas, correção de avaliações, presença em reuniões e eventos da escola, encontro de pais, entre tantos. Muitas vezes ele é professor no período noturno para complementar sua renda, desenvolvendo outra atividade durante o dia.

Os cursos de licenciatura também não são mais tão procurados nem atrativos. A desvalorização salarial, falta de autonomia, de condições mínimas de estrutura física e segurança nas escolas, falta de materiais básicos de trabalho são alguns fatores que determinam a rejeição por essa profissão. Por não possuírem uma posição social elevada, apesar da importância que é sua missão, sua imagem social acaba interferindo na escolha da profissão principalmente pelos jovens.

Profissão esta que passou e passa por mudanças significativas em relação ao professor não ser mais o centro detentor do conhecimento. Pelo contrário, informação imediata e conhecimento estão disponíveis aos alunos antes mesmo de irem para a escola por diversos outros meios. E para lidar com essa realidade, o professor precisa aprender a ser o mediador do que está disponível, e conduzir sua 
ação de modo que os alunos compreendam, busquem, participem, interagem e percebam o sentido e o significado do que está sendo desenvolvido/trabalhado a partir do que ele considerava já saber. O professor não precisa saber de tudo, mas estar atualizado o máximo possível tem sido uma preocupação e uma necessidade.

O professor é um sujeito de sentimentos e emoções carregadas com ele também no trabalho. Não há como separar. Assim, a satisfação ou não no seu trabalho intervém nas suas condições de saúde física e mental, na maneira como trabalha, na sua conduta, na sua vida fora da escola e, portanto, na sua casa e família. Ausência no trabalho ou mesmo abandono da profissão, improdutividade, falta de sentido e motivação no que faz até mesmo adoecer, podem ser decorrentes de insatisfação e descontentamento.

O trabalho é uma atividade que ocupa o tempo das pessoas e tem essas duas faces. Assim como pode promover a realização profissional, pessoal e financeira, o prazer e a satisfação em desenvolvê-lo, pode também ser motivador de insatisfação e causador de desgastes e doenças.

Diante do tema apresentado, surge a inquietação em responder a seguinte problemática: Quais os principais fatores condicionantes da (in)satisfação profissional dos professores do Curso de Educação Física da Faculdade La Salle de Lucas do Rio Verde MT?

A partir de então, buscou-se descobrir quais são os principais fatores condicionantes da (in)satisfação profissional dos professores do Curso de Educação Física da Faculdade La Salle de Lucas do Rio Verde MT. Partindo deste, insere-se os específicos: Conhecer as condições e organização de trabalho desses professores; Descobrir como se dá a relação interpessoal entre professores, com alunos, coordenação, direção e demais funcionários da Instituição; Identificar os fatores que intervêm na (in)satisfação profissional docente.

Com base nesses objetivos é que o presente trabalho de pesquisa foi organizado, onde se busca responder à questão norteadora considerando o referencial teórico e o caminho metodológico pretendido. 


\section{REVISÃO DE LITERATURA}

\section{Atuação profissional: o ser professor}

O trabalho faz parte da natureza humana, sendo o trabalho docente entendido/caracterizado como algo complexo e interativo dedicado e direcionado intencionalmente ao outro, sendo inevitável não ser atingido pelo próprio. Segundo Freire (1996, p.28) "toda prática educativa demanda a existência de sujeitos, um que, ensinando aprende, outro que, aprendendo, ensina”. Dessa maneira, o sujeito professor se transforma no e pelo trabalho, que "modifica a identidade do trabalhador, pois trabalhar não é somente fazer alguma coisa, mas fazer alguma coisa de si mesmo, consigo mesmo" (TARDIF, 2003, p.56). O exercício da profissão docente, em grande medida, é dependente da pessoa do professor, como pensa, age, sente, se comporta, em suas crenças, valores e experiências, ou seja, tem muitas de suas características.

O trabalho do professor não é estático, pelo contrário, é um processo dinâmico, desafiador e muitas vezes imprevisível. Sofre interferência de outros agentes educacionais, da cultura, economia, política, tecnologia, entre tantos. "Para além do espaço concreto da prática (sala de aula), o trabalho dos professores é condicionado pelos sistemas educativos e pelas organizações escolares em que estão inseridos" (NÓVOA, 1999, p. 71). Sacristán denuncia que os parâmetros gerais da profissão docente já estão definidos antes mesmo que ele se questione de como irá trabalhar. Segundo ele, o professor "atua em uma instituição rotineira, submetida a controles curriculares, dependente de livros-texto, sujeita à supervisão, que não lhes permite optar por alternativas que violentem esse marco de forma notável" (SACRISTÁN, 2000, p. 206).

Nesse cenário, ser professor constitui-se por saberes de diversas origens e espaços de formação. E esses saberes são um conjunto de capacidades, habilidades, caracterizando-se em saberes da formação profissional, saberes das diferentes disciplinas, saberes curriculares e saberes da própria experiência, derivados dos conhecimentos pessoais, escolares, da formação recebida, dos programas e manuais escolares e da experiência do trabalho, ambos ultrapassando os saberes da formação inicial apenas, o que o caracteriza como um saber plural, proveniente de fontes diversas (TARDIF, 2003). 
$\mathrm{Na}$ realização do seu trabalho, o professor utiliza desses saberes todos para planejar, definir metodologias, executar tarefas e avaliações, o que vai definindo sua identidade nesse processo incessante que é seu trabalho, e também com trocas de experiências. Conforme ressalta Tardif (2003, p. 49), na prática do seu trabalho, "o docente raramente atua sozinho, ele se encontra em interação com outras pessoas, a começar pelos alunos".

Dessa forma, a principal finalidade do trabalho docente é a aprendizagem em processo de interação. Trabalha nos mais diversos níveis e com as mais variadas situações. E em sua profissão, sempre vai encontrar o novo, independentemente de sua experiência e conhecimento. Além de trabalhar com o conhecimento sistematizado, tem o desafio de ensinar também para além da sala de aula, para que seus alunos sejam cidadãos responsáveis, críticos, reflexivos e capazes de enfrentar os desafios de que irão se deparar.

Sabendo que na escola convivem sujeitos totais e não apenas mentes sem história, sem corpo, sem identidades, também são equacionadas como conteúdo da docência, formar a curiosidade, a paixão de aprender, a emoção e vontade de conhecer, de indagar a realidade em que vivem, sua condição de classe, raça, gênero, sua idade, corporeidade, memória coletiva, sua diversidade cultural e social (ARROYO, 2000, p.120).

Para Savater (1998, p.147) "a humildade do professor consiste em renunciar a demonstrar o que está acima e em esforçar-se a ajudar os outros a subir. Seu dever é ajudar os outros a fazerem descobertas, e não se vangloriar das que ele fez". E isso vem ao encontro do que Freire (1996, p.21) defendia: "quando entro em uma sala de aula devo estar sendo um ser aberto a indagações, a curiosidades, às perguntas dos alunos, suas inibições; um ser crítico e inquiridor, inquieto em face da tarefa que tenho - a de ensinar".

Ensinar é, portanto, fazer escolhas constantemente em plena interação com os alunos. Ora, essas escolhas dependem da experiência dos professores, de seus conhecimentos, convicções e crenças, de seu compromisso com o que fazem, de suas representações a respeito dos alunos e, evidentemente, dos próprios alunos. (TARDIF, 2003, p. 132).

O trabalho docente é muito importante. É uma grande responsabilidade ao considerar que seus alunos dependem e esperam dele, muitas vezes visto como um modelo a ser seguido. Alunos estes com suas singularidades, diferentes modos de pensar, agir e ser, com diferentes histórias, ritmos, necessidades e interesses. O que reforça a concepção de Arroyo (2000, p.47), quando afirma que "todo ofício é uma 
arte reinventada que supõe sensibilidade, intuição, escuta, sintonia com a vida, com o humano", e na profissão docente, não é diferente.

A pergunta das mais sérias que um docente educador pode se fazer é o que fica, o que levam os educandos na caixa de ferramentas culturais acumuladas na escola para viver humanamente a vida (...). O que ficará a nos acompanhar são os conhecimentos aprendidos. Apenas os internalizados, registrados ou feito hábitos. O que levamos e nos será útil nas situações mais variadas da vida será uma mistura indefinida dos conteúdos aprendidos, dos conhecimentos postos em ação e dos hábitos internalizados. As habilidades simbólicas. A forma que damos à mente, à emoção, à memória e às atividades humanas com que construímos nossa história e a história. Com que nós construímos (ARROYO, 2000, p.11).

O trabalho docente é privilegiado. É uma profissão que requer e permite a aproximação mais humana e menos técnica com o outro, do que muitas outras profissões. "O fato de ensinar a nossos semelhantes e de aprender com nossos semelhantes é mais importante para o estabelecimento de nossa humanidade do que qualquer um dos conhecimentos concretos que assim se perpetuam ou se transmitem" (SAVATER, 1998, p. 40). Nas condições reais do seu trabalho, o professor transforma e se transforma, se constitui, se reinventa, constrói a sua identidade que vai muito além da formação que recebeu.

Uma boa parte do trabalho docente é de cunho afetivo, emocional. Baseiase em emoções, em afetos, na capacidade não somente de pensar nos alunos, mas igualmente de perceber e sentir suas emoções, seus temores, suas alegrias, seus próprios bloqueios afetivos (TARDIF, 2003, p. 130).

A atuação pedagógica do professor não se reduz apenas ao conhecimento teórico e conteúdo das diferentes disciplinas. Mas também à forma como o professor apresenta e desenvolve tudo isso, sua postura, sua afetividade e nas relações interpessoais estabelecidas. O que requer um exercício contínuo de reflexão. Libâneo (2011, p.45) defende que a cultura escolar envolve também a dimensão afetiva, que a "aprendizagem de conceitos, habilidades e valores envolve sentimentos, emoções, ligadas às relações familiares, escolares e aos outros ambientes em que os alunos vivem". E proporcionar essa aprendizagem aos alunos faz parte do trabalho docente. Este, precisa "conhecer e compreender motivações, interesses, necessidades de alunos diferentes entre si, capacidade de comunicação com o mundo do outro, sensibilidade para situar a relação docente no contexto físico, social e cultural do aluno" (LIBÂNEO, 2011, p. 45). 
Diante de tantas tarefas, vale reforçar que o trabalho docente, mais do que nunca, requer inovação e atualização constantes frente ao atendimento das exigências do desenvolvimento e da globalização, aliado às demandas de um ensino de qualidade, o que acaba descaracterizando-o, na maioria das vezes. Os condicionamentos e controles existem, mas "nunca evitam a responsabilidade individual de cada docente, porque não fecham por completo as opções para uma prática pedagógica melhorada, ao permitir margens em sua interpretação e possibilidades de resistência frente aos mesmos" (SACRISTÁN, 2000, p. 207). Com isso, e conforme essas questões são vistas e gerenciadas pelo docente, o mesmo pode sentir-se satisfeito ou não com e em seu trabalho, fatores que são apresentados e discutidos na sequência.

\section{Fatores de (in)satisfação no exercício da profissão docente}

Delimitar os fatores de insatisfação docente é uma tarefa difícil ao considerar não saber ao certo onde termina a satisfação para dar espaço à insatisfação, existindo, dessa forma, inúmeros fatores os quais tem sido objeto de pesquisas, apresentados e discutidos por alguns autores.

A satisfação, direta ou indiretamente, está relacionada à produtividade, qualidade do trabalho desempenhado, realização pessoal e profissional, e à saúde dos professores. Professor satisfeito dedica mais tempo e energia às tarefas desempenhadas e, consequentemente, há melhores resultados escolares.

Importante considerar que, atualmente, "o professor enfrenta críticas depreciadoras vindas de diversos pontos, levando a um incômodo desprestígio da sua profissão" (LIBÂNEO, 2011, p. 83). Além disso,

\footnotetext{
As condições precárias do trabalho, os péssimos salários, a falta de estabilidade, a condição de aulistas, o fraco ambiente cultural das escolas, a duplicidade de turnos de docência e ainda o trabalho doméstico (...) não apenas limitam a qualidade da docência, mas impossibilitam uma auto formação formadora. (ARROYO, 200, p.42)
}

Condições que estão deixando os professores desconfortáveis, inquietos, descrentes quanto ao sentido e significado da sua profissão levando-os, muitas vezes, a consequências como desmotivação pessoal e "elevados índices de absenteísmo e de abandono, insatisfação profissional traduzida numa atitude de desinvestimento e indisposição constante, [...] ausência de uma reflexão crítica sobre a ação profissional" (NÓVOA, p. 22, 1999). 
Ao se referir à situação em que os professores estão atuando nos últimos tempos, Esteve (1999) utiliza de uma metáfora de um grupo de atores, onde compara os professores como atores de determinada época, que sem serem avisados, o cenário muda desenrolando um novo pano de fundo no anterior (clássico e severo). Este novo cenário então é ofuscado por uma encenação pós-moderna, colorida e fluorescente que, inicialmente, surpreende e espanta os atores que se tornam agressivos querendo encontrar os responsáveis e uma explicação para tal. Mas não encontram os responsáveis, pelo contrário, são eles, os atores (professores), que deverão encontrar uma saída. E diante dessas situações imprevistas, o mal-estar, segundo o autor, é o que define o sentimento do elenco.

A expressão mal-estar docente é utilizada "para descrever os efeitos permanentes, de caráter negativo, que afetam a personalidade do professor como resultado das condições psicológicas e sociais em que exerce a docência, devido à mudança social acelerada" (ESTEVE, 1999, p. 98). Seu trabalho e ambiente de trabalho vêm sofrendo alterações expressivas resultantes das mudanças sociais, mas também econômicas e culturais, e que acaba transformando o trabalho do professor, alterando o seu papel e também o da escola.

A mudança acelerada do contexto social influi fortemente no papel a desempenhar pelo professor no processo de ensino, embora muitos professores não tenham sabido adaptar-se a essas mudanças, nem as autoridades educativas tenham traçado estratégias de adaptação, sobretudo ao nível de programas de formação de professores. O resultado é o desajustamento dos professores relativamente ao significado e alcance do seu trabalho (ESTEVE, 1999, p. 100).

Esteve (1999) assinala como indicadores 12 fatores ou elementos nessa mudança e que estão causando mal-estar e insatisfação dos professores, portanto, relacionados às mudanças na educação e na qualidade do ensino ofertado. São fatores que ajudam a compreender o porquê de tantas críticas à educação e à ação docente.

1: O aumento das exigências em relação às atribuições e responsabilidades do professor.

Esse fator é apontado pelo autor, considerando que os cursos de formação inicial não conseguem preparar adequadamente os professores para tal. Dos professores é esperado que domine o conhecimento específico da sua área de formação e que seja também um "facilitador da aprendizagem, pedagogo eficaz, organizador do trabalho de grupo, [...] cuide do psicológico e afetivo dos alunos, da 
integração social e da educação sexual, e a tudo a isso pode somar-se a atenção aos alunos especiais" (ESTEVE, 1999, p. 100).

2ำ Inibição educativa de outros agentes de socialização.

Este fator, para Esteve (1999), justifica-se pelo fato das famílias estarem com número reduzido de pessoas, e das mulheres estarem cada vez mais inseridas no mercado de trabalho, tendo menos tempo disponível para atender e conviver com seus filhos, ficando muitos valores essenciais de responsabilidade da família, transferidos para a escola. E este tem sido um fator de descontentamento dos professores que sentem estar assumindo uma função que não é sua.

Na mesma linha de pensamento,

Em relação ao seu papel institucional, as escolas precisam ampliar seus intercâmbios com a comunidade, com a cidade, com as empresas e outras instâncias profissionais precisam, ao mesmo tempo, redescobrir sua identidade para diferenciar-se de outras instituições educativas como família, mídias, organizações culturais (LIBÂNEO, 2011, p. 80).

3ํDesenvolvimento de fontes de informação alternativas à escola.

Tais fontes de informação, resultantes dos meios de comunicação de massa, reforça o fato de que o professor não é mais o único conhecedor ou detentor do conhecimento, "nem a escola detém sozinha o monopólio do saber. Há hoje um reconhecimento de que a educação acontece em muitos lugares, por meio de várias agências" (LIBÂNEO, 2011, p.27). Diante dessa realidade, cabe ao professor "integrar no seu trabalho o potencial informativo dessas novas fontes, modificando o seu papel tradicional” (ESTEVE, 1999, p. 101).

Agora, as crianças já chegam abarrotadas de mil notícias e visões multiformes, que não lhes custou nada adquirir [...], que receberam até sem querer! O professor tem de ajuda-los a organizar essa informação, combatêla parcialmente e oferecer-Ihes ferramentas cognitivas para torná-la proveitosa, ou, pelo menos, não nociva (ARROYO, 2000, p. 89).

Este tem sido mais um desafio para os professores. Para Masetto (2015), não cabe mais ao professor apresentar de forma organizada tais informações para que os estudantes as reproduzam em avaliações, ou seja, "hoje a questão é outra: como interagir com os alunos para que possam acessar as informações e com elas construir seu conhecimento" (MASETTO, 2015, p.33). Para tanto, os professores precisam estar em constante atualização e aperfeiçoamento, pois dele é exigido cada vez mais qualificação e competências. "Os jovens acessam o conhecimento e são bombardeados incessantemente por uma grande quantidade de informações 
[...], através dos aparelhos e recursos eletrônicos, sem a mediação do professor" (MASETTO, 2015, p. 15). Essa realidade faz com que os professores começam a pensar e a ter dúvidas sobre qual é a sua e o seu lugar função frente a isso. Porém,

A presença do professor torna-se indispensável para a criação das condições cognitivas e afetivas que ajudarão o aluno a atribuir significados às mensagens e informações recebidas das mídias, das multimídias e formas variadas de intervenção educativa urbana. O valor da aprendizagem escolar está justamente na capacidade de introduzir os alunos nos significados da cultura e da ciência por meio de mediações cognitivas e interacionais providas pelo professor (LIBÂNEO, 2011, p. 29).

\section{$4^{\circ}$ Ruptura do consenso social sobre a educação}

Este é outro fator de mudança apontado por Esteve (1999) quando se refere ao mal-estar docente. A instituição escolar está se descaracterizando pela presença cada vez mais forte de diferentes povos, culturas e modelos de socialização onde "o processo de socialização convergente em que se afirmava o caráter unificador da atividade escolar no campo cultural, linguístico e comportamental, foi substituído por um processo que obriga uma diversificação na atuação do professor" (ESTEVE, 1999 , p. 102). Assim, o professor precisa "vincular o trabalho que se faz na sala de aula com a vida que os alunos levam fora da escola e com as diferentes capacidades, motivações, formas de aprendizagem de cada um" (LIBÂNEO, 2011, p.42). Mais do que nunca, isso requer receber e acolher a diversidade cultural cada vez mais presente nas instituições escolares e salas de aula.

É levar em conta as experiências do cotidiano que os alunos têm na
condição de brancos, negros, homens, mulheres, homossexuais,
trabalhadores, pobres, remediados, e que não é possível atuar com todos
os alunos da mesma maneira. Trata-se de reconhecer que os resultados
escolares dos alunos dependem da origem social, da situação social e
familiar, da relação com os professores. [...] Atender a diversidade cultural
implica promover, efetivamente, a igualdade de condições e oportunidades
de escolarização a todos (LIBÂNEO, 2011, p. 43).

5 ำ Aumento das contradições no exercício da docência

Segundo Esteve (1999), a ação docente está ficando à mercê de críticas quanto a sua atuação e valores, pois este é frequentemente "confrontado com a necessidade de protagonizar papéis contraditórios que o obrigam a manter um equilíbrio instável [...], que desempenhe um papel de amigo, de companheiro e de apoio ao desenvolvimento do aluno" (ESTEVE, 1999, p. 103), muitas vezes difícil realmente de conciliar com suas funções. 
6ำ Mudança de expectativas em relação ao sistema educativo

O ensino não é mais direcionado apenas à elite ou parcela privilegiada da população, pelo contrário, caracteriza-se por um ensino de massa "muito mais flexível e integrador, mas incapaz de assegurar, em todas as etapas do sistema, um trabalho adequado ao nível do aluno" (ESTEVE, 1999, p. 103). Isso faz com que os estudantes complementem sua formação de outras formas e em outros locais para além da sala de aula, simplesmente.

$7^{0}$ Modificação do apoio da sociedade ao sistema educativo

Relacionado ao 6ำ fator, Esteve (1999) aponta mudanças também quanto ao apoio e reconhecimento da sociedade em relação ao ensino, e consequentemente, ao professor. Não acredita mais na educação como promissora de um futuro melhor, uma vez que este futuro é incerto e que a educação não conseguiu atingir igualmente a todos, nem aos mais desfavorecidos. Segundo o autor, grande parte da sociedade e os meios de comunicação "chegaram à conclusão simplista e linear de que os professores, como responsáveis diretos do sistema de ensino, são também os responsáveis diretos de todas as lacunas, fracassos, imperfeições e males que nele existem" (ESTEVE, 1999, p. 104).

$8^{\circ}$ Menor valorização social do professor

Já não existe mais o elevado status social e cultural por parte dos professores. Recebem salários pouco atrativos e o seu saber não é mais valorizado. A própria família dos estudantes reforça esse fator ao responsabilizar somente os professores em relação às dificuldades de aprendizagem de seus filhos, sendo seu trabalho "apreciado num sentido negativo [...], onde se tudo corre bem, os pais pensam que seus filhos são bons estudantes. Se as coisas correm mal, pensam que os professores são maus profissionais" (ESTEVE, 1999, p. 105), como se seus esforços não são valorizados.

9ํManças dos conteúdos curriculares

Esse tem sido outro fator responsável por situações de desconforto, mal-estar e insatisfação no trabalho pois, diante disso, os professores se encontram despreparados. Não é por acaso que isso acontece, mas "o extraordinário avanço das ciências e a transformação das exigências sociais requerem uma mudança profunda dos conteúdos curriculares" (ESTEVE, 1999, p. 106). Mas uma vez há a necessidade de que o professor esteja em contínua busca de formação, atualização e aprendizado, para não se sentir inseguro diante da sua tarefa de ensinar. 
$10^{\circ}$ Escassez de recursos materiais e deficientes condições de trabalho

Em muitas instituições de ensino públicas e privadas não existem materiais suficientes nem condições apropriadas de trabalho, o que contribui para a sensação de mal-estar docente, sendo que hoje em dia "o ensino de qualidade é mais fruto do voluntarismo dos professores do que consequência natural de condições de trabalho adequadas às dificuldades reais e às múltiplas tarefas educativas" (ESTEVE, 1999, p.106).

Nessa perspectiva, também "é difícil aos professores assumirem os requisitos profissionais e éticos da profissão com os baixos salários, com a preparação profissional deficiente, com a baixa autoestima que vai tomando conta da sua personalidade" (LIBÂNEO, 2011, p. 90). A questão econômica e a valorização salarial tem grande influência na satisfação docente e em qualquer outra profissão. Segundo Libâneo (2011, p. 93), "muitos problemas poderiam ser minimizados se a profissão de professor fosse bem remunerada".

$11^{\circ}$ Mudanças nas relações professor-aluno

Essas mudanças ocorreram principalmente nas últimas duas décadas (ESTEVE, 1999). Há uma falta de respeito e um aumento crescente de violência contra os professores nas escolas, fato que os deixa muito inseguros e preocupados. Atualmente, "o aluno pode permitir-se, com bastante impunidade, diversas agressões verbais, físicas e psicológicas aos professores ou aos colegas, sem que na prática funcionem os mecanismos de arbitragem teoricamente existentes" (ESTEVE, 1999, p. 107). Nem todas as escolas e professores sofrem com essas mudanças, pois, na maioria das vezes, este é um problema reflexo do "ambiente social dos bairros degradados ou das grandes cidades" (ESTEVE, 1999, p. 107), mas que de qualquer forma afeta toda a categoria.

$12^{\circ}$ Fragmentação do trabalho do professor

O último fator que contribui para o mal-estar docente, segundo Esteve (1999) refere-se à fragmentação do trabalho do professor. Segundo ele, por desempenharem grande número de atividades a eles atribuídas, estas, acabam muitas vezes sendo mal executadas devido à falta de tempo, o que leva à sobrecarga de trabalho e esgotamento profissional. Além das tarefas direcionadas às aulas, desempenham outras referentes à administração, precisam de tempo para "programar, avaliar, reciclar-se, orientar os alunos e atender os pais, organizar atividades várias, assistir a seminários e reuniões de coordenação, de disciplina ou 
de ano, porventura mesmo vigiar edifícios e materiais, recreios e cantinas" (ESTEVE, 1999, p. 108).

Quando discute a repercussão da mudança social e das tensões presentes no ensino na personalidade dos professores, Esteve (1999, p.112) afirma que, nessas condições, "os professores põem em jogo diversos mecanismos de defesa que baixam a qualidade da educação, mas que servem para aliviar a tensão a que o professor está submetido". E cita as principais consequências do mal-estar docente:

\begin{abstract}
Sentimentos de desajustamento e insatisfação perante os problemas reais da prática de ensino, em aberta contradição com a imagem ideal do professor; pedidos de transferência, como forma de fugir a situações conflituosas; desenvolvimento de esquemas de inibição, como forma de cortar a implicação pessoal com o trabalho que se realiza; desejo manifesto de abandonar a docência; absentismo laboral, como mecanismo para cortar a tensão acumulada; esgotamento; estresse; ansiedade; depreciação do eu; reações neuróticas; depressões. (ESTEVE, 1999, p. 113)
\end{abstract}

Todos esses fatores e muitos outros não mencionados, porém não menos importantes ou preocupantes, têm desencadeado nos professores níveis elevados de estresse e, consequentemente, um esgotamento físico e mental. A Síndrome de Burnout, como é chamada, afeta a saúde dos trabalhadores de modo geral, e com os professores não é diferente. Desencadeado em longo prazo, o Burnout ocorre já há algum tempo, desde "que a função de professor vem sendo associada a fatores sociais, psíquicos e econômicos, sendo estes reconhecidos hoje como importantes fatores de estresse" (BATISTA et al, 2010, p.504). Desse modo, na educação, intervém no alcance das finalidades pedagógicas, "levando os profissionais a um processo de alienação, cinismo, apatia, problemas de saúde e intenção de abandonar a profissão. Gera repercussões importantes no sistema educacional e na qualidade da aprendizagem" (BATISTA et al, 2010, p.504).

\title{
METODOLOGIA
}

A presente pesquisa classifica-se como qualitativa, uma vez que não emprega um "instrumental estatístico como base do processo de análise de um problema, não pretende enumerar nem medir unidades ou categorias homogêneas, (...) sendo uma forma adequada para entender a natureza de um fenômeno social" (RICHARDSON, 2012, p. 79). 
Quanto aos procedimentos técnicos, diante do tema apresentado e da situação particular, trata-se de um estudo de caso. Este, para Yin (2005), deve ter preferência quando do estudo de eventos contemporâneos, em situações em que os comportamentos relevantes não podem ser manipulados, sendo possível fazer observações diretas e entrevistas sistemáticas. Segundo o autor, "contribui, de forma inigualável para a compreensão que temos dos fenômenos individuais, organizacionais sociais e políticos, (...) e sua clara necessidade surge do desejo de se compreender fenômenos sociais complexos" (YIN, 2005, p. 21)".

O método de abordagem é o indutivo e a classificação da pesquisa com base nos objetivos é exploratória.

Os sujeitos da pesquisa foram 09 professores do Curso de Educação Física da Faculdade La Salle de Lucas do Rio Verde MT, atuantes nas três turmas em andamento do $1^{\circ}$ semestre/2018. No momento, havia 11 professores, porém, 02 não participaram.

Para a coleta dos dados, foi utilizado um questionário previamente elaborado de acordo com os objetivos da pesquisa. Neste, estavam questões abertas e fechadas, além de um espaço para outras considerações que os entrevistados julgassem pertinentes. Após a coleta de dados, as respostas dos entrevistados para cada questão foram organizadas em quadros, estas, agrupadas de acordo com cada objetivo específico pretendido. De modo a preservar a identidade dos respondentes, foi utilizada a nomenclatura P1 para professor um, P2 para professor dois e assim sucessivamente. As respostas das perguntas fechadas estão apresentadas em porcentagem, enquanto as respostas das perguntas abertas foram mantidas na íntegra.

\section{APRESENTAÇÃO E ANÁLISE DOS RESULTADOS}

\section{Caracterização dos sujeitos}

Os sujeitos da pesquisa são professores do Curso de Educação Física da Faculdade La Salle.

As primeiras questões do questionário enviado aos professores buscavam informações profissionais de modo geral. Quanto à graduação, apenas 3 possuem Educação Física como formação inicial. Os demais, são graduados em Filosofia, Letras, Química, Pedagogia e Biologia. Atuam no Curso de Educação Física pois 
possuem pós-graduação latu e strictu sensu em Educação e áreas afins. Quanto ao tempo de formação, esta, varia de 7 a 35 anos. O que não corresponde ao tempo de serviço, que está entre 4 e 37 anos. O que significa que tem professor que começou atuar antes mesmo de terminar a formação inicial. $O$ tempo de serviço na instituição varia de 18 meses a 12 anos. Porém, 5 professores atuam também em outra instituição de ensino.

Com essas informações, é possível assegurar que os professores já têm experiência suficiente para falar sobre satisfação e insatisfação no exercício da sua profissão. Mesmo que alguns tenham menos tempo de formação e atuação, provavelmente já se depararam com inúmeras situações, positivas e/ou negativas, características de um ambiente onde tem um sistema a seguir e obedecer, onde tem diferentes pessoas e setores envolvidos com questões burocráticas a seguir, onde tem alunos, os mais diversos, sob sua responsabilidade acadêmica.

\section{Condições e organização do trabalho}

Conhecer as condições e organização de trabalho dos professores foi 0 primeiro objetivo específico. Na tentativa de respondê-lo, foram feitas três perguntas aos professores acerca da estrutura física e materiais oferecidos pela Instituição, sobre a autonomia conferida a eles para organizar e planejar seu trabalho, além do seu envolvimento e participação nas questões e decisões que envolvem o curso. Essas questões com suas respectivas respostas são apresentadas nos quadros abaixo:

Quadro 1 - Estrutura física e materiais

\begin{tabular}{|c|c|}
\hline \multicolumn{2}{|r|}{$\begin{array}{l}\text { Questão: Considera a estrutura física e os materiais oferecidos pela instituição } \\
\text { adequados para o seu trabalho? }\end{array}$} \\
\hline $100 \%$ & Sim \\
\hline \multicolumn{2}{|c|}{ Comente sua resposta. } \\
\hline $\mathrm{P} 1$ & Tenho tudo que preciso para ministrar minhas aulas. \\
\hline P2 & A instituição dá ótimo suporte ao trabalho. \\
\hline P3 & $\begin{array}{l}\text { Meu trabalho nunca foi inviabilizado pela falta de materiais. Pelo contrário, } \\
\text { sempre que solicitado, é providenciado. }\end{array}$ \\
\hline $\mathrm{P} 4$ & $\begin{array}{l}\text { Em ambas as Instituições sim. Embora, em uma das que trabalho disponho de } \\
\text { material e estrutura de qualidade. }\end{array}$ \\
\hline P5 & A instituição presa para que os materiais estejam sempre à disposição. \\
\hline
\end{tabular}




\begin{tabular}{|l|l|}
\hline P6 & $\begin{array}{l}\text { Tenho materiais de multimídia disponíveis, estrutura física adequada e em } \\
\text { condições de higiene adequadas, materiais de apoio para disponibilizar para os } \\
\text { acadêmicos, bem como meios de comunicação on-line. Apenas poderia ter mais } \\
\text { livros na biblioteca em variedade. }\end{array}$ \\
\hline P7 & São excelentes em termos Administrativos e Acadêmicos. \\
\hline P8 & $\begin{array}{l}\text { Tenho o material que necessito para as minhas aulas, livros disponíveis na } \\
\text { biblioteca, material para aulas práticas. }\end{array}$ \\
\hline P9 & tenho todo material que necessito sempre que solicito. \\
\hline
\end{tabular}

Fonte: Dados da pesquisa, 2018.

Conforme as respostas apresentadas no quadro, percebe-se claramente que a instituição fornece os materiais e espaço adequados para os professores desenvolverem suas aulas. Relatam que os materiais necessários estão sempre à disposição e caso solicitam algo que não tenha, logo são atendidos. Um dos professores cita que além do espaço e dos materiais de qualidade, tem também disponíveis meios de comunicação on-line, além de os serviços de higiene serem satisfatórios.

Arroyo (2000), ao discutir sobre o ofício dos professores/mestres, defende que "criatividade e competência não faltam. Faltam em muitas escolas condições materiais, tempos e espaços, bibliotecas, remuneração e estímulo. Falta uma organização do trabalho mais coletiva, menos solitária" (p. 122). O que não acontece nem é a realidade da instituição pesquisada, segundo dados da pesquisa.

Sabe-se que a educação depende em grande medida do professor. Mas o que a ele é oferecido e disponibilizado também contribui para o sucesso ou não do seu trabalho. Se o ambiente e as condições sobre as quais desenvolvem o seu trabalho influenciam nos resultados e objetivos traçados, certamente irão influenciar também no seu nível de satisfação e bem-estar. E isso está evidente nas respostas dos professores ao responderem que são satisfatórias e adequadas as condições de trabalho a eles proporcionadas e a atenção dispensada quando solicitam materiais e/ou equipamentos. Significa que a instituição está atenta e preocupada com os profissionais que ali estão e, em compensação, com a qualidade do trabalho que ali exercem. 
Fatores condicionantes da (in)satisfação docente no curso de educação física da faculdade La Sale Lucas do Rio Verde

Quadro 2 - Autonomia na organização e planejamento do trabalho

\begin{tabular}{|l|l|}
\hline \multicolumn{2}{|l|}{ Questão: Possui autonomia para organizar e planejar o seu trabalho? } \\
\hline $100 \%$ & Sim \\
\hline Comente sua resposta. \\
\hline P1 & Organizo meu cronograma, convidados, aulas externas. \\
\hline P2 & Somos incentivados na dinamização do trabalho acadêmico \\
\hline P3 & $\begin{array}{l}\text { Desde que contemple as ementas das disciplinas, tenho total autonomia no } \\
\text { planejamento e execução das atividades }\end{array}$ \\
\hline P4 & $\begin{array}{l}\text { Em ambas Instituições tenho a liberdade (desde que respeitando os referidos } \\
\text { PPP's) em desenvolver o meu trabalho docente }\end{array}$ \\
\hline P5 & $\begin{array}{l}\text { Pelas funções exercidas, possuo autonomia necessária para planejar e executar } \\
\text { as tarefas pertinentes ao cargo. }\end{array}$ \\
\hline P6 & $\begin{array}{l}\text { Como em qualquer instituição de ensino tem a ementa do curso para seguir, mas } \\
\text { dentro disso pode ser planejada as aulas da forma que considero mais adequada } \\
\text { para a minha disciplina. }\end{array}$ \\
\hline P7 & A autonomia abrange as funções e responsabilidades que tenho na Instituição. \\
\hline P8 & $\begin{array}{l}\text { Faço meu plano de aula e modifico se houver necessidade, mas sem a } \\
\text { intervenção da direção. }\end{array}$ \\
\hline P9 & Sim. \\
\hline
\end{tabular}

Fonte: Dados da pesquisa, 2018.

Conforme as respostas apresentadas no quadro, percebe-se que os professores têm total liberdade para organizar e planejar seu trabalho. Relatam que os planejamentos são realizados tendo como base a ementa da disciplina. Um dos professores cita que a autonomia abrange também outras funções e responsabilidades que tem na instituição.

Para Sacristán (2000, p. 207), a autonomia conferida aos professores é muito importante na realização do seu trabalho, pois estes "podem ser reprodutores de situações e instituições herdadas ou trabalhar para transformá-las - tão real é a determinação externa quanto à autonomia profissional”. E a falta de autonomia muitas vezes pode ser um fator que antecede à insatisfação.

Condições insuficientes para o exercício da autonomia reduz a capacidade dos professores de iniciativa e de tomada de decisão sobre a organização e desenvolvimento do seu ensino, o que faz com que o ensino tradicional e a falta de motivação do docente quanto ao seu aperfeiçoamento profissional permaneçam. Por outro lado, a autonomia para planejar seu trabalho contribui para o sucesso do 
mesmo, desde que esteja também de acordo com a ementa do curso. Se o professor tem autonomia e planeja seu trabalho, consequentemente tem mais chances de atingir sucesso nos objetivos traçados. E certamente irá influenciar na sua satisfação docente e no bem-estar profissional. Isso está claro nas respostas dos professores que parecem satisfeitos com a liberdade e confiança proporcionadas no momento de planejar. Significa que a instituição está colaborando para o bem-estar dos professores no que tange este quesito, mesmo que este esteja submetido a um controle burocrático e administrativo.

Quadro 3 - Envolvimento e participação nas decisões e organizações pedagógicas Questão: Você se envolve/participa das decisões e organização pedagógica no curso em que trabalha?

\begin{tabular}{|l|l|}
\hline $89 \%$ & Sim \\
\hline $11 \%$ & Não \\
\hline Comente sua resposta. \\
\hline P1 & $\begin{array}{l}\text { Tudo que será ou poderá ser modificado no curso é discutido com os docentes } \\
\text { nas reuniões de colegiado. }\end{array}$ \\
\hline P2 & $\begin{array}{l}\text { Ocorrem periódicas reuniões de colegiado, semana acadêmica semestral, } \\
\text { formações de professores. }\end{array}$ \\
\hline P3 & $\begin{array}{l}\text { Na reformulação do PPC, no planejamento de atividades que envolvem o Curso, } \\
\text { projetos de extensão e ações comunitárias. }\end{array}$ \\
\hline P4 & $\begin{array}{l}\text { Como a pergunta anterior se refere à Instituição de Ensino Superior irei apenas } \\
\text { reportar minha resposta a esta. Sim, tenho voz nas reuniões de Curso. }\end{array}$ \\
\hline P5 & Coordenando as ações e articulando com a equipe de professores. \\
\hline P6 & $\begin{array}{l}\text { Nas reuniões de colegiado por exemplo temos a oportunidade de propor e discutir } \\
\text { com os colegas estratégias de organização, propor atividades acadêmicas para } \\
\text { docentes e discentes. A instituição está aberta para sugestões. }\end{array}$ \\
\hline P7 & $\begin{array}{l}\text { A participação é nas reuniões do Colegiado do Curso e encontros com o } \\
\text { Coordenador e professores do Curso. }\end{array}$ \\
\hline P8 & $\begin{array}{l}\text { Os planos são discutidos entre a coordenação e os professores para um melhor } \\
\text { andamento do curso. }\end{array}$ \\
\hline solicitada em alguns casos.
\end{tabular}

Fonte: Dados da pesquisa, 2018.

Conforme as respostas apresentadas no quadro, 89\% dos professores participam e se envolvem em reuniões para decidir e organizar 0 trabalho pedagógico. Os outros $11 \%$, que corresponde a um professor somente, respondeu 
não participar, o que é justificado por ele quando comenta que sua disciplina é no segundo semestre, e que por isso não participa dos encontros no primeiro. Relatam que tudo o que é discutido e decidido é para o melhoramento do serviço prestado para o público alvo em termos de organização, reformulação de documentos, planejamento das aulas e ações que envolvem o curso como um todo. E que essas discussões acontecem, de modo geral, nas reuniões de colegiado com a coordenação.

Sobre isso, Paro (1996) defende que se deve ter claro que os professores, assim como os demais integrantes da comunidade escolar, se sentem mais interessados pela tarefa, que no caso é o processo decisório, quando é dada a eles a oportunidade de decidir, escolher e dar opiniões sobre a mesma, sendo assim evidente que se tornem mais motivados a participar do processo, pois o sentimento de pertença e importância prevalece.

Sabe-se que é de suma importância que cada professor dê a sua opinião na hora de decidir o andamento do curso, cada qual tem sua visão e sua compreensão para contribuir de alguma forma. Se os professores participam e decidem juntos, melhora a qualidade do serviço prestado e, certamente, irá influenciar na sua satisfação e também do público alvo. Como a maioria dos professores participa das reuniões, a faculdade também ganha em conhecimento agregado nesses encontros. Significa que a realidade dos professores da pesquisa caracteriza-se pela participação democrática e coletiva das decisões que dizem respeito à organização do curso em questão, possibilitando que se sintam integrantes efetivos de uma unidade em busca de objetivos comuns. Que as decisões não são postas pelos superiores e simplesmente acatadas. Pelo contrário, existe um ambiente favorável para discussões, questionamentos, reflexões, diálogo e busca por melhores resultados.

Em uma instituição de ensino, nesse caso de ensino superior, espaço privilegiado de relações e formação humana, onde também se encontra e se socializa o saber institucionalizado e sistematizado, os professores são membros fundamentais e indispensáveis para o bom andamento de um curso. Permitir que tenham espaço na tomada de decisões e organização de um curso os valoriza como profissionais e fortalece a unidade como um todo. 


\section{Relação interpessoal entre professores, com os alunos, coordenação, direção e demais funcionários da Instituição}

Descobrir como se dá a relação interpessoal entre professores, com os alunos, coordenação, direção e demais funcionários da Instituição foi o segundo objetivo desta pesquisa, considerando que as relações interpessoais estabelecidas no ambiente de trabalho influenciam em grande medida a satisfação ou insatisfação do professor com seu trabalho. As respostas obtidas estão apresentadas na sequência:

Quadro 4 - Relações interpessoais entre professores

\begin{tabular}{|l|l|}
\hline \multicolumn{2}{|l|}{ Questão: Comente como acontecem as relações interpessoais entre: Professores } \\
\hline P1 & De forma impessoal. \\
\hline P2 & $\begin{array}{l}\text { Ocorre ótima integração: sala dos professores, datas comemorativas, reuniões, } \\
\text { encontros de planejamento e formação. }\end{array}$ \\
\hline P3 & $\begin{array}{l}\text { Empática e agradável, mesmo que nossos encontros se resumam apenas pelos } \\
\text { corredores, intervalos ou reuniões. }\end{array}$ \\
\hline P4 & $\begin{array}{l}\text { Dentro da ética profissional. No curso em questão vai depender do Campus no } \\
\text { qual está lecionando. }\end{array}$ \\
\hline P5 & $\begin{array}{l}\text { Através de encontro formadores e ações diretas. } \\
\text { de maneira geral somos todos civilizados e educados com o próximo. }\end{array}$ \\
\hline P6 & $\begin{array}{l}\text { Penso que mantemos boas relações interpessoais, há o espaço para o diálogo e } \\
\text { responsabilidade diferenciadas para cada um. com }\end{array}$ \\
\hline P8 & $\begin{array}{l}\text { Cada professor tem relacionamento mais restrito com os professores pertencentes } \\
\text { ao curso ao qual está vinculado. }\end{array}$ \\
\hline P9 & $\begin{array}{l}\text { Quase não nos vemos devido espaço que trabalhamos ser na escola e não na } \\
\text { unidade onde tem outros cursos. }\end{array}$ \\
\hline
\end{tabular}

Fonte: Dados da pesquisa, 2018.

Quadro 5 - Relações interpessoais entre professor e alunos

\begin{tabular}{|l|l|}
\hline \multicolumn{2}{|l|}{ Questão: Comente como acontecem as relações interpessoais entre: Professor e alunos } \\
\hline P1 & $\begin{array}{l}\text { Depende de cada professor. Eu tento conhecer, aproximar-me, para saber suas } \\
\text { dificuldades e facilidades. }\end{array}$ \\
\hline P2 & Aulas, encontros de formação, festas de formaturas, datas comemorativas... \\
\hline P3 & $\begin{array}{l}\text { Preocupante. Como se o professor não conseguisse contribuir para que seus } \\
\text { alunos atribuíssem sentido e significado ao que é proposto nas diferentes }\end{array}$ \\
\hline
\end{tabular}


Fatores condicionantes da (in)satisfação docente no curso de educação física da faculdade La Sale Lucas do Rio Verde

\begin{tabular}{|l|l|}
\hline & disciplinas. \\
\hline P4 & Embasados no diálogo. Contudo, os conflitos se fazem presentes. \\
\hline P5 & $\begin{array}{l}\text { Há liberdade nessa relação. recomenda-se apenas aos professores que fiquem } \\
\text { atentos aos princípios, missão e visão da instituição. }\end{array}$ \\
\hline P6 & $\begin{array}{l}\text { Posso falar da minha relação interpessoal com os alunos, penso que há diálogo, e } \\
\text { a comunicação esteve sempre aberta pelos meios on-line, WhatsApp entre outras } \\
\text { formas de comunicação. As relações de amizade são desenvolvidas, mas sem } \\
\text { deixar que isso interfira nas funções e obrigações de cada um na relaço } \\
\text { professor e aluno. }\end{array}$ \\
\hline P7 & São relações de produtividade e crescimento de docentes e acadêmicos. \\
\hline P8 & $\begin{array}{l}\text { As vezes acho q falta respeito por parte dos discentes e falta maior conhecimento } \\
\text { entre os direitos deveres. }\end{array}$ \\
\hline P9 & $\begin{array}{l}\text { Falando de minha pessoa é ótima tenho sempre 95\% de frequência nas minhas } \\
\text { aulas, e tenho bom relacionamento com todos, nunca em tive problemas com os } \\
\text { mesmos. }\end{array}$ \\
\hline
\end{tabular}

Fonte: Dados da pesquisa, 2018.

Quadro 6 - Relações interpessoais entre professor e superiores

\begin{tabular}{|l|l|}
\hline \multicolumn{2}{|l|}{ Questão: Comente como acontecem as relações interpessoais entre: Professor e } \\
superiores (coordenação, administração, direção acadêmica e geral)
\end{tabular}

Fonte: Dados da pesquisa, 2018.

Quadro 7 - Relações interpessoais entre professor e demais funcionários Questão: Comente como acontecem as relações interpessoais entre: Professor e demais funcionários 


\begin{tabular}{|l|l|}
\hline P1 & Vejo que é boa. \\
\hline P2 & Prestação de serviços, reuniões de planejamento \\
\hline P3 & $\begin{array}{l}\text { Pouco contato, porém, de forma amigável. Sempre que solicitado algo aos } \\
\text { mesmos, prontamente somos atendidos. }\end{array}$ \\
\hline P4 & Imagino que maior parte dentro da esfera profissional. \\
\hline P5 & Normalmente em função de serviços prestados e encontro formadores. \\
\hline P6 & $\begin{array}{l}\text { Novamente uma relação de diálogo e respeito pois todos estamos trabalhando } \\
\text { para a educação de sujeitos. Além disso desenvolvemos atividades em grupo } \\
\text { como prática esportiva, comemorações. }\end{array}$ \\
\hline P7 & $\begin{array}{l}\text { As relações são de integração e produtividade, uns interagindo com os outros. Os } \\
\text { funcionários sendo suporte para o Corpo Docente, que cumprem a principal } \\
\text { função da Instituição que é a formação integral dos alunos. }\end{array}$ \\
\hline P8 & $\begin{array}{l}\text { As vezes temos problemas com burocracia, mas na pedida do possível são } \\
\text { solucionados. }\end{array}$ \\
\hline P9 & Excelente \\
\hline
\end{tabular}

Fonte: Dados da pesquisa, 2018.

Conforme as respostas apresentadas, observa-se que as relações interpessoais entre os professores acontecem de diversas formas, na sala dos professores, em datas comemorativas, encontros e outras atividades acadêmicas. De modo geral, com empatia, respeito, ética e cooperação. Um professor (a) comenta que as relações são melhores com os professores que atuam no mesmo curso e outro diz que quase não vê seus colegas de trabalho devido a sua atuação ser em outra unidade da instituição.

Quando questionados a respeito de como acontecem as relações entre eles e seus alunos, respondem que tem relações construtivas e embasadas em diálogos, mas que os conflitos estão presentes. Outros, por sua vez, dizem que as relações estão preocupantes, um professor ainda diz que é como se não pudesse contribuir para que seus alunos atribuíssem sentido para o conteúdo proposto. Diferentemente dos demais, um dos professores, provavelmente por não ter entendido a pergunta, respondeu onde ocorrem as relações entre professores e alunos, e não como estas ocorrem.

Ao responderem sobre as relações estabelecidas com os superiores (coordenação e direção acadêmica, administrativa e geral), os professores demostram que existe um certo distanciamento físico durante o semestre, mas que conseguem manter contato via e-mail e que sempre são atendidos conforme suas 
necessidades. Além disso, manifestam em suas respostas que esta relação se dá nos encontros ou reuniões, sempre com respeito, diálogo e profissionalismo.

Da mesma forma, as relações entre os professores e os funcionários da Instituição acontecem de forma respeitosa, prestativa, com diálogo e de forma amigável. Os professores respondem que se encontram com os funcionários pelos corredores, nos encontros de formação, reuniões e comemorações. Apenas um dos professores relata o fato de, às vezes, ter problemas com burocracia que, na pedida do possível, são solucionados.

As respostas vêm ao encontro de que "o existir na vida cotidiana é estar continuamente em interação e comunicação com os outros e os significados próprios são partilhados com os significados das outras pessoas, que vivem também 0 cotidiano" (CUNHA, 1992, p. 36). Nessa perspectiva, a constituição do sujeito, suas características individuais, como personalidade, hábitos, modos de agir, capacidade mental, etc., dependem de suas interações com o meio social em que vive (REGO, 2000).

$\mathrm{Na}$ interação harmoniosa e agradável com os demais sujeitos da instituição, professores, alunos, superiores e demais funcionários, percebe-se que valores essencialmente humanos são preservados e praticados: respeito, cooperação, confiança, diálogo, apoio. Significa que os professores da pesquisa têm ajuda e suporte no seu trabalho, gerando segurança, e, deste modo, satisfação em realizálo, mesmo com alguns contratempos e conflitos que acontecem, conforme algumas respostas, principalmente em relação aos alunos.

Quadro 8 - Interferência das relações interpessoais no trabalho docente

\begin{tabular}{|l|l|}
\hline \multicolumn{2}{|l|}{$\begin{array}{l}\text { Questão: Você considera que as relações interpessoais estabelecidas no ambiente de } \\
\text { trabalho interferem no desenvolvimento do mesmo? }\end{array}$} \\
\hline $100 \%$ & Sim \\
\hline Comente sua resposta. \\
\hline P1 & Se eu sinto-me bem onde trabalho, quero voltar, sinto-me feliz em ajudar. \\
\hline P2 & $\begin{array}{l}\text { As relações interpessoais influenciam no psíquico e animam ou desanimam na } \\
\text { prestação de serviços e relações humanas. }\end{array}$ \\
\hline P3 & $\begin{array}{l}\text { Quando se trabalha com pessoas e entre pessoas, as relações ali estabelecidas } \\
\text { influenciam diretamente do trabalho desenvolvido, considerando que para se } \\
\text { obter êxito, é necessário diálogo, ouvir e respeitar o que o outro tem a dizer, } \\
\text { colaborar com o outro e estabelecer uma relação de confiança. }\end{array}$
\end{tabular}


Fatores condicionantes da (in)satisfação docente no curso de educação física da faculdade La Sale Lucas do Rio Verde

\begin{tabular}{|l|l|}
\hline P4 & $\begin{array}{l}\text { Uma Instituição de Educação é feita por gente. Portanto, considerar as relações } \\
\text { deve ser um princípio mister. }\end{array}$ \\
\hline P5 & $\begin{array}{l}\text { Ambiente tranquilo, equilibrado e de confiança, proporcionam rendimento } \\
\text { esperado por todos e de todos. }\end{array}$ \\
\hline P6 & $\begin{array}{l}\text { Pois como trabalhar com sujeitos sem interagir como os mesmos, o bem estar } \\
\text { no ambiente de trabalho está relacionado também ao bom relacionamento entre } \\
\text { seus membros. }\end{array}$ \\
\hline P7 & $\begin{array}{l}\text { Quanto melhor as relações interpessoais, melhor o desenvolvimento do } \\
\text { ambiente e a realização da missão institucional. }\end{array}$ \\
\hline P8 & $\begin{array}{l}\text { Se você não tem um bom relacionamento dentro do seu ambiente de trabalho, } \\
\text { as atividades ficam prejudicadas. É muito ruim não se sentir integrante da } \\
\text { instituição. }\end{array}$ \\
\hline P9 & $\begin{array}{l}\text { Não podemos ter um relacionamento maior por trabalhar em uma unidade } \\
\text { separada da sede. }\end{array}$ \\
\hline
\end{tabular}

Fonte: Dados da pesquisa, 2018.

Por unanimidade, os professores reconhecem que as relações interpessoais estabelecidas no ambiente de trabalho interferem no desenvolvimento do mesmo. De modo geral, comentam que ao se relacionar e trabalhar com pessoas, é importante se sentir bem, que prevaleça o respeito, o ouvir e ser ouvido, colaborar, confiar e se sentir pertencente daquele ambiente. Um dos professores enfatiza que se ele se sentir bem no local do seu trabalho, ele quer voltar, ajudar, e isso o faz feliz. Uma das professoras reclama que por trabalhar em outra unidade da Instituição, não tem um relacionamento maior com os integrantes da mesma.

Vygotsky (2008) considera que as mudanças que ocorrem no homem, ao longo do seu desenvolvimento, estão associadas às interações estabelecidas com o meio e com os sujeitos que nele pertencem e participam, com a cultura e histórias de vida que ali se apresentam. Para a constituição e desenvolvimento do sujeito tem que haver a participação do outro, portador da própria cultura. Desse modo, a interação com o outro é importante não só no processo de construção do conhecimento, mas na constituição do próprio sujeito. "Podemos aprender a ler, escrever sozinhos, podemos aprender geografia e a contar sozinhos, porém não aprendemos a ser humano sem a relação e o convívio com outros humanos que tenham aprendido essa difícil tarefa" (ARROYO, 2000, p. 54).

Assim, compreende-se, juntamente aos professores, que as relações interpessoais estabelecidas no ambiente de trabalho são propícias à forma como 
irão se sentir e realizar a missão a qual escolheram. No caso pesquisado, essas relações estão influenciando, em grande medida, positivamente.

\subsection{Fatores que intervêm na (in) satisfação profissional docente}

O último objetivo específico desta pesquisa foi identificar os fatores que intervêm na (in) satisfação profissional docente. Para respondê-lo, aos professores foram feitas quatro questões, apresentadas nos próximos quadros, bem como suas respostas.

Quadro 9 - Satisfação com a profissão

\begin{tabular}{|l|l|}
\hline \multicolumn{2}{|c|}{ Questão: Você se sente satisfeito com sua profissão? } \\
\hline $66 \%$ & Sim \\
\hline $34 \%$ & Parcialmente \\
\hline
\end{tabular}

Fonte: Dados da pesquisa, 2018.

Segundo as respostas do quadro, a maioria dos professores está satisfeita com a profissão. Mesmo assim, 34\% dos entrevistados sentem-se parcialmente satisfeitos.

Foi pensando nessa possibilidade que as próximas questões foram feitas, conforme segue:

Quadro 10 - Fatores responsáveis pela satisfação

\begin{tabular}{|l|l|}
\hline \multicolumn{2}{|l|}{ Questão: Qual(is) são os principais fatores responsáveis pela sua satisfação? } \\
\hline P1 & A relação com os acadêmicos e os seus progressos. \\
\hline P2 & Desenvolver as atividades pelas quais me preparei longamente. \\
\hline P3 & $\begin{array}{l}\text { Fazer o que eu gosto, contribuir com a formação de meus alunos, estar sempre } \\
\text { desafiada a estudar mais, estar entre as pessoas. }\end{array}$ \\
\hline P4 & Relevância da Profissão. \\
\hline P5 & Realização pessoal, produção acadêmica e resultados verificados. \\
\hline P6 & Faço algo que eu gosto, não estou professora eu sou professora. \\
\hline P7 & Para mim, ser educador é uma missão e a realizo como tal. \\
\hline P8 & Verificar o aprendizado dos alunos. \\
\hline P9 & $\begin{array}{l}\text { Amor e prazer em que sinto, ao passar aos acadêmicos o ensinamento de ser um } \\
\text { bom professor, e não apenas estar professor! }\end{array}$ \\
\hline
\end{tabular}

Fonte: Dados da pesquisa, 2018.

De modo geral, os principais fatores responsáveis pela satisfação dos professores entrevistados, conforme suas respostas, referem-se ao fazer o que gostam, contribuir com os acadêmicos e acompanhar o progresso, aprendizado, 
formação e resultados dos mesmos. Há manifestação de que a profissão é uma missão, prazerosa e desafia a estudar mais. Um dos professores (P4) responde que o motivo é a relevância da profissão.

Os fatores apontados pelos professores são compreendidos como sentimentos positivos em relação à ação docente, com as experiências vividas e objetivos alcançados. É possível perceber fatores afetivos envolvidos nesse processo, do próprio professor e também em relação aos alunos. Sentem-se elementos da sua profissão e responsáveis por ela, por uma educação de qualidade e pelo fato de estarem contribuindo e ensinando a alguém. Significa que os professores entrevistados ao deixarem evidente sua satisfação, provavelmente farão com que os alunos também se manifestem e se caracterizem dessa forma. Ou seja, a satisfação dos docentes é um fator decisivo da satisfação dos alunos.

Quadro 11 - Fatores responsáveis pela insatisfação

\begin{tabular}{|l|l|}
\hline \multicolumn{2}{|l|}{ Questão: Qual(is) são os principais fatores responsáveis pela sua insatisfação? } \\
\hline P1 & O salário dos professores no Brasil. \\
\hline P2 & Excesso de direitos por parte de alguns. \\
\hline P3 & $\begin{array}{l}\text { Remuneração, indisciplina e falta de interesse e compromisso por parte da maioria } \\
\text { dos estudantes, descaracterização da profissão. }\end{array}$ \\
\hline P4 & Desvalorização social, econômica, e saúde do Professor. \\
\hline P5 & Normalmente falta de apoio na formação e políticas públicas. \\
\hline P6 & $\begin{array}{l}\text { Penso que minha insatisfação se dá com aquele que não se propõem a aprender, } \\
\text { com o aluno que apenas se faz presente, mas não quer realmente aprender. }\end{array}$ \\
\hline P7 & Não vejo fatores de insatisfação. \\
\hline P8 & Falta de respeito e em alguns casos falta de comprometimento com as atividades. \\
\hline P9 & $\begin{array}{l}\text { Trabalhar em unidade separada acho que poderia ser o mesmo espaço físico com } \\
\text { a outra (ginásio de esportes). }\end{array}$ \\
\hline
\end{tabular}

Fonte: Dados da pesquisa, 2018.

Ao responderem sobre o que causa insatisfação na profissão, os professores reclamam da remuneração, descaracterização da profissão e falta de apoio, trabalhar em unidade separada dos demais professores e, conforme a maioria, o fator aluno causa insatisfação. Este, quando demonstra indisciplina, falta de interesse, de compromisso e de respeito. $O$ professor 4 , que na questão da satisfação reconhece a profissão como relevante, agora responde que o que o deixa insatisfeito é a desvalorização social, econômica e para com a saúde do professor. 
A questão salarial influencia muito na satisfação docente e em qualquer outra profissão. "Admitindo ou não, um salário digno satisfaz em relação às necessidades mais básicas como despesas diárias de casa e alimentação, e pelo que o dinheiro proporciona em relação às necessidades de auto realização, como viajar, por exemplo" (MARCOLAN et al, 2017, p.94).

A complexidade do trabalho docente torna visível os desafios diários enfrentados por eles. Além do fator remuneração (baixa), a indisciplina cresce ao nível da insatisfação. Esta, segundo Esteve (1999, p.108), "que do ponto de vista psicológico, é um problema que assume grandes proporções, provocando um sentimento de insegurança e mal-estar entre os professores". Convém destacar que a indisciplina, cada vez mais crescente, é um dos fatores responsáveis pelo insucesso escolar e estabelece, do mesmo modo, um fator de insatisfação para os professores. Percebe-se que pelas respostas obtidas, a indisciplina e o desinteresse desgastam os professores, que se preocupam, que se sentem frustrados ou até mesmo impotentes frente a essa realidade.

Quadro 12 - Insatisfação e qualidade do trabalho

\begin{tabular}{|c|c|}
\hline \multicolumn{2}{|r|}{ Questão: Você considera que a (in)satisfação compromete a qualidade do seu trabalho? } \\
\hline $66 \%$ & Sim \\
\hline $34 \%$ & Não \\
\hline \multicolumn{2}{|c|}{ Comente sua resposta } \\
\hline P1 & $\begin{array}{l}\text { Eu sou professora porque amo o que faço. Mas, por outro lado, temos que lutar } \\
\text { pela nossa valorização. }\end{array}$ \\
\hline P2 & Desmotiva, confunde a execução de projetos \\
\hline P3 & $\begin{array}{l}\text { Professores satisfeitos trabalham motivados, buscam por melhorias, } \\
\text { aprofundamento e atualização. Sentem-se realizados profissional e pessoalmente. }\end{array}$ \\
\hline P4 & $\begin{array}{l}\text { É preciso dedicação para enfrentar as dificuldades inerentes a toda e qualquer } \\
\text { profissão. Contudo, o mal-estar docente se dá pela limitações postas: a) leis que } \\
\text { dificultam o desempenho das atividades; b) falta de interesse da clientela } \\
\begin{array}{llll}\text { (alunos/acadêmicos); } & \text { c) desvalorização e desrespeito da clientela } \\
\text { (alunos/acadêmicos); } & \text { d) desvalorização e desrespeito da sociedade; } \\
\text { desvalorização; e) desrespeito das instituições políticas. }\end{array}\end{array}$ \\
\hline P5 & A satisfação melhora e rendimento e a insatisfação proporciona desmotivação. \\
\hline P6 & $\begin{array}{l}\text { Visto que minha insatisfação está diretamente relacionada com a reciprocidade do } \\
\text { aluno em querer aprender, penso que a qualidade do meu trabalho não fica } \\
\text { comprometida visto que utilizo de diferentes metodologias a fim de atingir a todos }\end{array}$ \\
\hline
\end{tabular}




\begin{tabular}{|l|l|}
\hline & os alunos. \\
\hline P7 & Não desenvolvo a insatisfação pessoal no meu trabalho. \\
\hline P8 & $\begin{array}{l}\text { Uma pessoa insatisfeita não realiza um bom trabalho, não consegue manter o } \\
\text { foco e a vontade de se dedicar ao trabalho. }\end{array}$ \\
\hline P9 & $\begin{array}{l}\text { Nosso foco é ensinamento aos acadêmicos, não importa onde fazemos isso, e sim } \\
\text { como fazemos com amor e prazer. }\end{array}$ \\
\hline
\end{tabular}

Fonte: Dados da pesquisa, 2018.

A maioria dos professores respondeu que a (in)satisfação compromete a qualidade do seu trabalho. Segundo eles, a insatisfação desmotiva, não permite que realizem um bom trabalho, faz perder o foco, a vontade de se dedicar. Novamente a falta de disciplina e interesse pelos alunos causa desmotivação e interfere no trabalho, desvaloriza. Por outro lado, um dos professores respondeu não estar insatisfeito, enquanto outro destaca que o seu trabalho é feito com amor e prazer. Além destes, houve a manifestação de que "professores satisfeitos trabalham motivados, buscam por melhorias, aprofundamento e atualização. Sentem-se realizados profissional e pessoalmente".

As respostas dos professores admitem que a realização e satisfação no trabalho "envolvem sentimentos e emoções singulares que influenciam diretamente sobre o trabalhador, pois afetam e interferem na sua saúde física e mental, no seu comportamento e desempenho profissional, repercutindo também na sua vida pessoal e familiar" (MARCOLAN et al, 2017, p.85).

Conforme o que foi descrito, pode-se ter uma ideia de que realmente a (in)satisfação afeta o trabalho e a sua qualidade, e, não menos importante, a condição de bem-estar física e emocional dos professores. Os mesmos, precisam se adaptar às novas exigências, aceitar as mudanças sem medo ou inibição. $E$ os professores demonstram que mesmo diante de fatores negativos, realizam o seu trabalho com amor, não desistem quando mencionam buscar pela sua valorização e ainda procuram desenvolver diferentes metodologias. São atitudes que os renova permanentemente e fazem valer a pena a profissão que escolheram!

\section{CONSIDERAÇÕES FINAIS}

Diante do atual cenário que envolve a profissão docente, e conforme a literatura consultada, muitos fatores do contexto social e institucional onde a função é exercida são determinantes da satisfação ou insatisfação profissional. Nesse 
sentido, pode-se considerar, a partir das respostas dos professores, que esses fatores são contemplados positivamente e que, portanto, sentem-se satisfeitos. As condições físicas que a Instituição oferece são adequadas e suficientes para o desenvolvimento do seu trabalho sem afetar a qualidade do mesmo, participam ativamente nas decisões e organização do Curso juntamente com a coordenação, e possuem autonomia para o planejamento e realização das aulas, o que ficou evidente nas suas respostas.

De modo geral, todos se relacionam de forma respeitosa, agradável e responsável. Cada um em seu setor ou função, mas todos procurando fazer o seu melhor para que o ambiente seja acolhedor e prazeroso. Apenas um dos professores menciona quase não ter esse convívio, exceto com os estudantes, por trabalhar a sua disciplina em outra unidade da Instituição. Convém destacar que, pela lógica, esse professor não está isolado por completo, ele deve ter contato com os demais nas reuniões do Curso, nos encontros de formação pedagógica no início de cada semestre, nos eventos e comemorações da Instituição, conforme eles mesmos mencionaram.

Ficou evidente nas respostas que a maioria está satisfeito com a profissão e com os fatores que assim permitem estar: ser professor e desempenhar essa missão com amor, estar entre as pessoas e poder ajudá-las, contribuir de alguma forma para a formação dessas, realização profissional. Por outro lado, mesmo que apenas 34\% manifestam-se parcialmente satisfeitos, 8 de 9 professores não deixaram de mencionar o que os deixa insatisfeitos. Nesse caso, o que prevaleceu foi a questão salarial e o desinteresse dos estudantes. Diante disso, a maioria dos professores reconhece que estar satisfeito ou não está diretamente relacionado à qualidade do seu trabalho.

Através dessa pesquisa foi possível descobrir que os professores atuam em uma Instituição e em um Curso que contribuem para a sua satisfação e realização pessoal e profissional. Mesmo que em alguns pontos encontram-se insatisfeitos, os fatores promotores da satisfação se sobressaem e permitem que os professores ainda se encantem pela profissão que escolheram e a assumam com compromisso, preocupação com o outro e responsabilidade. Ensinar e estar com o outro é uma tarefa que requer, também, afetividade e apreço pelo trabalho. $E$ isso é muito importante que os professores consigam manter. 
Destaca-se, por enquanto, que necessidades, dificuldades e angústias dos professores não podem jamais ser nem permanecer ignoradas, considerando seu bem-estar físico e emocional, além da qualidade do trabalho desempenhado. Não menos importante que isso, há de se considerar ainda que essa profissão é merecedora de todo o respeito e estima especial por todos.

\section{REFERÊNCIAS}

ARROYO, M. G. Ofício de mestre: imagens e outo-imagens. Petrópolis, RJ: Vozes. 2000.

BATISTA, J.B.V.; CARLOTTO, M.S., COUTINHO, A.S., AUGUSTO, L.G.S. Prevalência da Síndrome de Burnout e fatores sociodemográficos e laborais em professores de escolas municipais da cidade de João Pessoa, PB. Revista Brasileira de Epidemiologia.- Vol 13 - N. 03. São Paulo, 2010. Disponível em: <http://www.scielo.br/pdf/rbepid/v13n3/13.pdf>. Acesso em: Mar. 2018.

CUNHA, Maria Isabel da. 0 bom professor e sua prática. 2 ed. Campinas, SP: Papirus, 1992.

ESTEVE, J, M. Mudanças sociais e função docente. IN: NÓVOA, A. (Org.). Profissão professor. Porto: Porto Editora, 1999.

FREIRE, P. Pedagogia da autonomia: saberes necessários à prática educativa. São Paulo: Paz e Terra, 1996.

LIBÂNEO, J. C. Adeus professor, adeus professora? : novas exigências educacionais e profissão docente. - 13 ed. - São Paulo: Cortez, 2011.

MARCOLAN, S. G.; MARTINS, G. V.; ESPÍNDOLA, M.; JULIANI, T.C.; Docência: fatores indicativos de insatisfação na contemporaneidade. ÁGORA Revista Eletrônica, Cerro Grande RS. Ano XIV, oㅡ 25, p. 84-96, Dez de 2017. Disponível em: < http://agora.ceedo.com.br/ojs/index.php/AGORA_Revista_Eletronica>. Acesso em: Ago. 2018.

NÓVOA, A. Formação de Professores e Profissão Docente. In: NÓVOA, A. (Coord.). Os Professores e a sua Formação. Lisboa: Dom Quixote, 1999. p. 20-17.

Professor se forma na escola. Nova Escola, São Paulo, no 142, Maio/2001,

PARO, V. H. Eleição de diretores de escolas públicas: Avanços e Limites da Prática. Revista Brasileira de Estudos Pedagógicos, Brasília, v. 77, n. 186, p. 376-395, maio/ago 1996. Disponível em: < 
Fatores condicionantes da (in)satisfação docente no curso de educação física da faculdade La Sale Lucas do Rio Verde

http://rbep.inep.gov.br/index.php/rbep/article/view/1084/1058>. Acesso em: Set. 2018.

REGO, T. C. A origem da singularidade humana na visão dos educadores.

Cadernos Cedes, ano XX, no 35, Julho/2000, p. 96-113.

RICHARDSON, R. J. Pesquisa Social: métodos e técnicas. -3- ed. - São Paulo: Atlas, 2012.

SACRISTÁN, J. G. Plano do currículo, plano do ensino: o papel dos professores/as. In: SACRISTÁN, J. G.; PÉREZ GÓMEZ, A. I. Compreender e transformar o ensino. Tradução Ernani F. da Fonseca Rosa - 4. Ed. - Artmed: Porto Alegre, 2000.

SAVATER, F. O Valor de Educar. Tradução de Monica Stahel. São Paulo: Martins Fontes, 1998.

TARDIF, M. Saberes docentes e formação profissional. Petrópolis, RJ: Vozes, 2003.

VYGOTSKY, L.S. Pensamento e Linguagem. São Paulo: Martins Fontes, 2008.

YIN, R. K. Estudo de caso: planejamento e método. $3^{\text {a }}$ Ed. Porto Alegre:

Bookmann, 2005. 